\title{
Influence of growth regulators and nutritional composition on the embryoidogenesis process in Rubus chamaemorus L. in micropores in vitro culture
}

\author{
Dmitry Zontikov ${ }^{1 *}$ Igor Krinitsyn ${ }^{1}$, Svetlana Zontikova ${ }^{1}, K_{\text {senia }}$ Malakhova ${ }^{1}, A$. \\ Baghizadeh $^{2}, P$. Behroozi ${ }^{2}$ and Roman Sergeev ${ }^{3}$ \\ ${ }^{1}$ Kostroma State University, 156000, 14, 1st of May St., Kostroma, Russia \\ ${ }^{2}$ Kerman, Graduate University of Advanced Technology, 7631818356, Iran \\ ${ }^{3}$ Volga State Technological University, 424000, 3. Lenin Sq., Yoshkar-Ola, the Republic of Mari El, \\ Russia
}

\begin{abstract}
The effect of growth regulators and nutrient composition on the embryoidogenesis of Rubus chamaemorus L. (hermaphroditic cultivar Nubu and male plants selected in the Kostroma region) was studied. The density of microspores in the suspension was about 80000 pieces in $1 \mathrm{ml}$ of a sterile aqueous solution with glucose. It was found that for the use of 2,4dichlorophenoxyacetic acid at a concentration of $0.2 \mathrm{mg} / \mathrm{l}$, it is possible to obtain up to $33 \pm 2$ pcs. embryoids at a microspore density of 80000 in 0.5 $\mathrm{ml}$ of a sterile glucose solution. In an experiment on the influence of the mother liquor of the nutrient medium on the growth of embryoids, it was found that of the available combinations, more intensive growth processes took place on the nutrient medium with a reduced content of macronutrients to $2 / 3$ of the base MS medium.
\end{abstract}

\section{Introduction}

Cloudberry (Rubus chamaemorus L.) is a valuable berry crop that has been used relatively recently as a plantation crop $[1,2]$. At present, cloudberry breeding mainly proceeds in two directions, the first is the search for highly productive male and female plants, the second is the search for, in natural conditions, hermaphroditic individuals that have the ability not to lose this feature over time [3]. So over the past decade, high-yielding male varieties Apollen and Apolto and female Fjellgull and Fjordgull were created, and the famous hermaphroditic variety Nubu was also created [4]. The acceleration of the selection work can be done using plants with a doubled haploid set of chromosomes [5].

The use of doubled haploids in breeding makes it possible to obtain homozygous lines in 2-3 years [6], obtaining stable homozygous lines from a population facilitates the search for rare genotypes, and also helps to clarify issues of non-allelic compliment [7].

* Corresponding author: zontikovdn@mail.ru 
There are currently no works on the androklinia $R$. chamaemorus L. At the same time, the methods of this work are similar for most species: temperature (high and low temperatures) and chemical (most often growth regulators), treatment of donor plants, optimization of the composition of the nutrient medium, growth regulators, carbohydrate components, selection of the optimal anther development stage and microspores.

The purpose of our work was to study the influence of the composition of the nutrient medium on the androklinia of $R$. arcticus $\mathrm{L}$., to obtain haploid plants for use in the breeding process.

\section{Materials and methods}

In work, we used the hermaphroditic variety Nubu and also male plants selected in the Nerekhta district of the Kostroma region.

Microspores were isolated from anthers, which were selected from buds of different ages and sizes. In our work, we used both buds collected in natural conditions and obtained by distillation in a laboratory [8].

Sterilization of generative shoots was carried out according to the scheme: 1.5 minutes in a $70 \%$ aqueous solution of ethanol, after 12 minutes they were sterilized in a $4 \%$ aqueous solution of sodium hypochlorite and washed in three vessels with sterile water, $100 \mathrm{ml}$ each. Microspores from anthers were isolated mechanically using Potter-Elvehjem's homogenizer (Sigma-Aldrich, Boston, USA). with a volume of $1.5 \mathrm{ml}$, after which $0.5 \mathrm{ml}$ of sterile water with glucose was added at a concentration of 20-30 g/l, centrifuged at a rotation speed of 4500-5500 rpm. and microdosing was transferred to nutrient media to activate embryoidogenesis. The density of the microspores in the suspension was about 80000 pieces in $1 \mathrm{ml}$ of a sterile aqueous solution with glucose; 50 pieces of anthers were crushed to obtain a similar density. We used anthers with a length of 12 to $15 \mathrm{~mm}$; this size is typical for buds 5-10 days before blooming.

The counting of microspores / pollen grains was carried out using a Goryaev camera [9]. In the calculations, only pollen grains isolated from the anther were taken into account a day before the flower opened. Anthers were counted in 130 flowers. The amount of pollen was counted in 50 anthers.

The microspore culture method includes several stages, at each of which the composition of the nutrient medium and the growth regulators used are changed. When introduced into the culture in vitro to activate morphogenesis, we used the nutrient medium MS [10] and WPM medium supplemented with $100 \mathrm{mg} / \mathrm{l}$ mesoinositol, $2 \mathrm{mg} / 1$ glycine, 0.5 $\mathrm{mg} / \mathrm{l}$ thiamine, $0.5 \mathrm{mg} / \mathrm{l}$ pyridoxine, $30 \mathrm{~g} / \mathrm{l}$ glucose and $5.0 \mathrm{~g} / \mathrm{l}$ agar, $\mathrm{pH} 3.8$. We studied the effect on the morphogenesis of various concentrations of the growth regulator: 6benzylaminopurin (BAP) in a concentration of 0.50 to $2.00 \mathrm{mg} / \mathrm{l}$ and 2,4dichlorophenoxyacetic acid (2,4-D) in a concentration of 0,1 to $0.4 \mathrm{mg} / 1$ [11]. After the appearance of embryoids, MS medium was used with the content of macro- and microelements in full concentration and reduced to $2 / 3$ and $1 / 2$ of the base medium.

For the cultivation of microspores, at the stage of introducing into the culture in vitro, growth and development of embryoids, $10 \mathrm{ml}$ glass culture vessels were used. At the stage of growth of regenerated plants, culture vessels with a volume of $100 \mathrm{ml}$ were used. The cultivation of microspores, embryoids, and regenerated plants was carried out under illumination of 1500 Lux and a period of $16 \mathrm{~h}$ (day) $/ 8 \mathrm{~h}$ (night) at a temperature not exceeding $25^{\circ} \mathrm{C}$.

Chromosome counting was performed using the meristem zone of the roots of regenerated plants. The meristematic zone of the roots was placed in the Carnoy retainer, which was kept for 24 hours. Then it was washed for 20 minutes under running water. Then it was placed in a mixture of enzymes (pectinase- $0.3 \%$, macerase- $0.3 \%$, cellulase- $0.3 \%+$ 
citrate buffer). They put it in a water bath - at a temperature of $+37^{\circ} \mathrm{C}$ for two hours, after the roots for three minutes they placed in $60 \%$ acetic acid, where the material was crushed with a dissecting needle, circled with a 3: 1 fixative, shaken, washed in absolute alcohol, painted in methylene blue and washed in distilled water. After that, chromosome counting was performed $[11,12]$.

The experimental data are presented in the form of arithmetic mean values (M) indicating the error of the mean $( \pm$ SEM) and coefficient of variation $(\mathrm{Cv})$. The calculation of the confidence interval based on the t-distribution of Student at a significance level of 0.05 was carried out using the statistical package of Microsoft Excel 2010.

\section{Results}

In the flowers on male plants collected by us in the Nerekhta district, the number of anthers varied from 45 to 62 pcs., The average number of pollen grains in the anther was $1579 \pm$ 124. In the hermaphroditic variety Nubu, the variation in the number of anthers ranged from 34 to 55 units, and the average number of pollen grains was $1695 \pm 253$. We have identified 4 main stages of the development of microspores: 1 stage - tetrad; stage 2 unvacuated with a centrally localized core; stage 3 - highly vacuolated - with a thick wall, large vacuole and a small, laterally located nucleus; stage 4 - three-cell pollen.

After placing microspores on a nutrient medium, the formation of embryoids was observed on $59 \pm 2$ days of cultivation in the Nubu hermaphroditic variety, in this version with $0.2 \mathrm{mg} / 1$ 2,4-D, the number of formed embryoids was $33 \pm 2$ pieces per 80000 microspores. In male plants selected under natural conditions, the best indices were with the same content of 2,4-D, embryoids were observed on $50 \pm 1$ days, and their number was 52 \pm 5 pieces in the best case (Table 1). Visually, embryoids were noted starting from the heart stage when they reached a size of $0.5 \mathrm{~mm}$. There was no significant effect of the genotype of those used by us on the morphogenesis of microspores in culture. We did not study the influence of the developmental stage on the activity of morphogenesis, but the vast majority of microspores placed on a nutrient medium were at the stage of unvacuated microspores.

Table 1. The effect of the growth regulator of 6-benzylaminopurine and 2,4-dichlorophenoxyacetic acid on the morphogenesis of $R$. chamaemorus microspores (MS nutrient medium, sucrose $30 \mathrm{~g} / \mathrm{l}, \mathrm{pH}$ 3.8 ; microspore density 80000 in $0.5 \mathrm{ml}$, “-” explant death)

\begin{tabular}{|c|c|c|c|c|}
\hline \multirow{2}{*}{$\begin{array}{c}\text { The growth } \\
\text { regulator } \\
\text { concentration, } \\
\mathrm{mg} / \mathrm{l}\end{array}$} & \multicolumn{2}{|c|}{ The appearance of embryoids, days } & \multicolumn{2}{|c|}{$\begin{array}{l}\text { The number of embryoids formed on the } \\
\text { 60th day, pcs. }\end{array}$} \\
\hline & $\mathrm{M} \pm \mathrm{SEM} 1,2$ & $\mathrm{Cv}, \%$ & $\mathrm{M} \pm \mathrm{SEM} 1,2$ & $\mathrm{Cv}, \%$ \\
\hline \multicolumn{5}{|c|}{ Sort Nubu } \\
\hline \multicolumn{5}{|c|}{ 2,4-dichlorophenoxyacetic acid } \\
\hline 0.1 & $67 \pm 2^{\mathrm{a}}$ & 4.8 & $16 \pm 1$ & 3.2 \\
\hline 0.2 & $59 \pm 1$ & 4.9 & $33 \pm 2^{\mathrm{ab}}$ & 7.3 \\
\hline 0.3 & $69 \pm 2^{\mathrm{ab}}$ & 9.0 & $25 \pm 2^{\mathrm{ab}}$ & 5.4 \\
\hline 0.4 & $72 \pm 4^{\mathrm{abc}}$ & 3.2 & $9 \pm 3$ & 2.3 \\
\hline \multicolumn{5}{|c|}{ 6-benzylaminopurine } \\
\hline 0.5 & - & - & - & - \\
\hline 1.0 & - & - & - & - \\
\hline 1.5 & $74 \pm 2^{\mathrm{a}}$ & 4.7 & $8 \pm 2^{a}$ & 4.5 \\
\hline 2.0 & $75 \pm 3^{\mathrm{ab}}$ & 5.2 & $7 \pm 3^{\text {ab }}$ & 8.2 \\
\hline \multicolumn{5}{|c|}{ Male form from a natural population } \\
\hline \multicolumn{5}{|c|}{ 2,4-dichlorophenoxyacetic acid } \\
\hline 0.1 & $63 \pm 3$ & 9.1 & $15 \pm 3$ & 4.4 \\
\hline 0.2 & $50 \pm 1$ & 10.2 & $52 \pm 5$ & 7.3 \\
\hline
\end{tabular}




\begin{tabular}{|c|c|c|c|c|}
\hline 0.3 & $66 \pm 1$ & 6.3 & $32 \pm 1$ & 5.1 \\
\hline 0.4 & - & - & - & - \\
\hline \multicolumn{5}{|c|}{ 6-benzylaminopurine } \\
\hline 0.5 & - & - & - & - \\
\hline 1.0 & $87 \pm 12^{\mathrm{a}}$ & 17.2 & $4 \pm 1^{\mathrm{a}}$ & 9.5 \\
\hline 1.5 & $89 \pm 9^{\mathrm{a}}$ & 13.5 & $8 \pm 2^{\mathrm{a}}$ & 5.7 \\
\hline 2.0 & - & - & - & - \\
\hline
\end{tabular}

Note. Each experiment was performed in triplicate. Dashes mean the death of explants. 1 - confidence interval based on student t-distribution at a significance level of $0.05 ; 2$ - the values in the column marked with the same lowercase letters $(\mathrm{a}, \mathrm{b}, \mathrm{c})$ do not have a significant difference at the $5 \%$ significance level $(\mathrm{P} \leq 0.05)$ according to the t-student test

In the experiment on the influence of the mother liquor of the nutrient medium on the growth of embryoids, it was found that of the available combinations, more intensive growth processes took place on the nutrient medium with a reduced content of macronutrients to $2 / 3$ of the base MS medium. In this variant, embryoid growth was observed already on the 34th day of cultivation; on the 40th day, the embryoid size reached $5.5 \mathrm{~mm}$ (see Table 2).

Table 2. The effect of the concentration of the mother liquor of nutrient media MS and WPM on the development of $R$. chamaemorus embryoids (growth regulator 2,4-dichlorophenoxyacetic acid, sucrose $30 \mathrm{~g} / \mathrm{l}$, pH 3.8; microspore density 80000 in $0.5 \mathrm{ml}$, “-" the death of explants)

\begin{tabular}{|c|c|c|c|c|}
\hline \multirow{2}{*}{$\begin{array}{c}\text { The concentration } \\
\text { of the base } \\
\text { solution, } \%\end{array}$} & $\begin{array}{c}\text { The beginning of embryoid } \\
\text { growth*, day }\end{array}$ & $\begin{array}{c}\text { Total length after } 40 \text { days of } \\
\text { cultivation, mm }\end{array}$ \\
\cline { 2 - 5 } & $\mathrm{M} \pm$ SEM1,2 & $\mathrm{Cv}, \%$ & $\mathrm{M} \pm$ SEM1,2 & $\mathrm{Cv}, \%$ \\
\hline \multicolumn{5}{|c|}{ sort Nubu } \\
\hline MS & $47 \pm 1^{\mathrm{a}}$ & 4.8 & $2.2 \pm 1.5^{\mathrm{a}}$ & 3.2 \\
\hline $2 / 3 \mathrm{MS}$ & $34 \pm 2$ & 4.9 & $5.5 \pm 1.0$ & 7.3 \\
\hline $1 / 2 \mathrm{MS}$ & $45 \pm 1^{\mathrm{a}}$ & 9.0 & $3.1 \pm 1.0^{\mathrm{a}}$ & 5.4 \\
\hline \multicolumn{5}{|c|}{ Male form from a natural population $^{\mathrm{a}}$} \\
\hline WPM & $67 \pm 1.0^{\mathrm{a}}$ & 9.1 & $1.1 \pm 1.0^{\mathrm{a}}$ & 14.4 \\
\hline $2 / 3 \mathrm{WPM}$ & $66 \pm 1.0^{\mathrm{ab}}$ & 10.2 & $1.2 \pm 0.8^{\text {ab }}$ & 17.3 \\
\hline $1 / 2 \mathrm{WPM}$ & $70 \pm 1.0^{\mathrm{ab}}$ & 6.3 & $0.9 \pm 0.3^{\mathrm{ab}}$ & 15.1 \\
\hline
\end{tabular}

Note. Each experiment was performed in triplicate. Dashes mean the death of explants. 1 - confidence interval based on student t-distribution at a significance level of $0.05 ; 2$ - the values in the column marked with the same lowercase letters $(a, b)$ do not have a significant difference at the $5 \%$ significance level $(\mathrm{P} \leq 0.05)$ according to the $\mathrm{t}$-student test

In the obtained regenerant plants, ploidy was checked by counting the number of chromosomes and the number of chloroplasts in the closing stomata cells. The variation of chloroplasts in the closing stomata cells in diploid plants is from 8 to 12, haploid from 2 to 6.

\section{Conclusion}

To obtain haploid regenerated plants of $R$. chamaemorus $\mathrm{L}$., it is advisable to use a nutrient medium with a reduced content of macronutrients to $2 / 3$ of the share of the base MS medium, supplemented with a growth regulator of 2,4-dichlorophenoxyacetic acid at a concentration of $0.2 \mathrm{mg} / \mathrm{l}$, which will allow receive up to $33 \pm 2$ pieces of embryoids per 80000 microspores. For the further development of embryoids, it is also necessary to use the nutrient medium MS in full, or reduced to $2 / 3$ of the share of the base medium.

The work was supported by the RFBR grant 20-016-00134 A. 


\section{References}

1. H. Kokko, H. Teittinen and S. Kärenlampi, Revegetation of peatland for cloudberry cultivation, in Proceedings of the 12th International Peat Congress, Tampere, Finland, 6 to 11 June 2004, Jyväskylä, Finland. (2004)

2. G. Nilsen, International Journal of Fruit Science, 5, 45-60 (2006)

3. E. Uleberg, G. Rothe and I. Martinussen, Latvian Journal of Agronomy, 12, 122-125 (2009)

4. K. Rapp and I. Martinussen, Acta horticulturae, 585, 159-160, (2001)

5. N.N. Kruglova, T.B. Batygina, V.Yu. Gorbunova, G.E. Titova, O.A. Seldimirova, Embryological basis of androkline of wheat, 97 (2005)

6. O.A. Seldimirova In vitro embryoid and embryo morphogenesis wheat, 23 (2002)

7. J.G. Duijs, R.E. Voorrips, Euphytica, 60, 45-55 (1992)

8. D.Zontikov, S.Zontikova, R.Sergeev and A.Shurgin In vitro propagation of Rubus chamaemorus L. and Rubus arcticus. Proc. Int. Conf. «14th International multidisciplinary scientific geoconference and EXPO». Albena, 397-403 (2014)

9. I.A. Kondratieva and V.D. Samuilova, Workshop on immunology, 224 (2001)

10. T. Murashige and F. Skoog Revised, Physiologia Plantarum, 15, 473-97, (1962)

11. D. Zontikov, Sel'skokhozyaistvennaya Biologiya, 55, 128-136 (2020)

12. V.A. Pukhalsky, A.A. Soloviev, V.N. Yurtsev, Cytology and cytogenetics of plants, 118 (2004) 